\title{
Condensation of 2-hydroxy-2'-aminoacetophenone to form a dihydropyrazine
}

\author{
Anthony R. Butler* and Elaine H. Brown \\ School of Chemistry, University of St. Andrews, St. Andrews, Fife, KY16 9ST, UK \\ E-mail:arb3@st-and.ac.uk
}

Dedicated to Douglas Lloyd on the occasion of his $80^{\text {th }}$ birthday

\begin{abstract}
In the condensation of two molecules of 2-hydroxy-2'-aminoacetophenone to form a dihydropyrazine the slow, rate-determining step has been shown, by spectral and kinetic means, to be reaction of two molecules of aminoketone to form an aminoalcohol.
\end{abstract}

Keywords: Dihydropyrazine formation, aminoketone condensation, reaction kinetics

\section{Introduction}

Condensation of two molecules $\alpha$-aminoketone to form a dihydropyrazine (Scheme 1$)^{1}$ must be a multistep process:

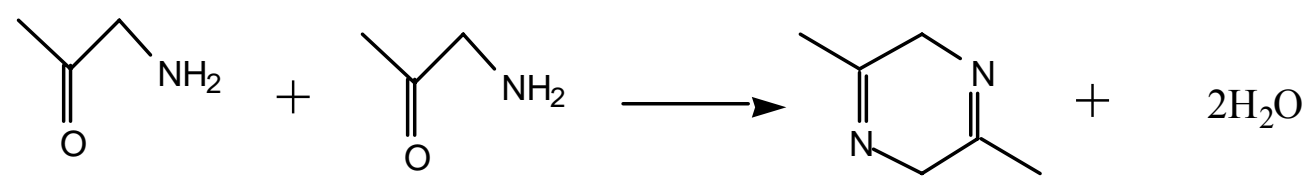

\section{Scheme 1}

A possible sequence for the condensation of two molecules of an aromatic $\alpha$-aminoketone (1) is shown in Scheme 2 with two aminoalcohol intermediates, 2 and 3. 


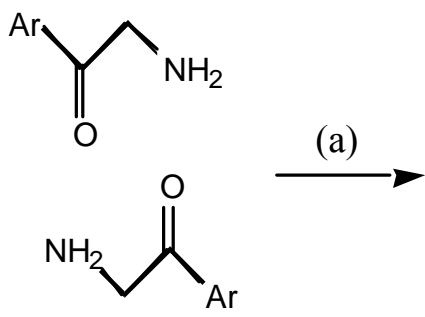

(1)

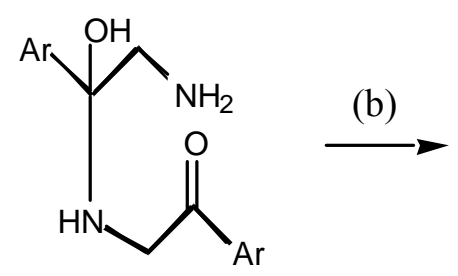

(2)

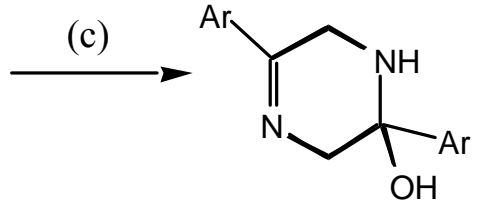

(3)

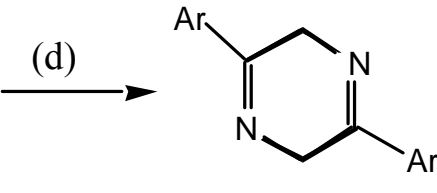

$\operatorname{Ar}=$

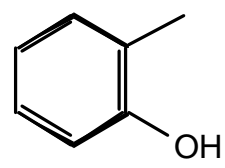

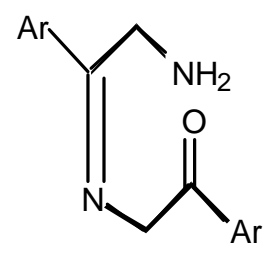

(4)

\section{Scheme 2}

In principle, any one of the steps (a) to (d) could be the slow, rate-determining process. As an alternative mechanism, dimerisation could involve the enolic form of the aminoketone (5).

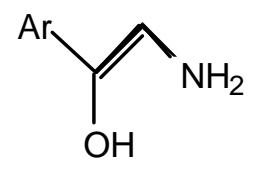

(5)

If that were the case then the slow, rate-determining step could be enolisation of a single molecule of aminoketone. A study of the spectral changes accompanying reaction, and a determination of the rate law governing the kinetics of reaction, should contribute to a delineation of the mechanism. The condensation of two molecules of 2-hydroxy-2'aminoacetophenone (1) to give 2,5-dihydro-3,6-di(2'-hydroxyphenyl)pyrazine (4) was chosen for study as it contains a convenient chromophore.

\section{Results and Discussion}

The substrate (1) was prepared by a modification of the method of the Huebner and Link ${ }^{2}$ and the synthesis is outlined in Scheme 3. Addition of one equivalent of $\mathrm{KOH}$ to a solution of $\mathbf{8}$ gave the free base 1 which rapidly condensed to give a precipitate of dihydropyrazine 4 . This 
compound, which had a very low solubility in all the solvents examined, was characterised by Huebner and Link. ${ }^{2}$<smiles>O=c1cc(O)c2ccccc2o1</smiles><smiles>C[13CH]</smiles>

(c)<smiles>NCC(=O)c1ccccc1O</smiles>

(b)<smiles>O=C(C[N+](=O)[O-])c1ccccc1O</smiles>

(7)

(8)

Scheme 3. (a) $\mathrm{HNO}_{3} / \mathrm{CH}_{3} \mathrm{CO}_{2} \mathrm{H}$; (b) $\mathrm{NaOH} / \mathrm{HCl}$; (c) $\mathrm{SnCl}_{2} / \mathrm{HCl}$.

Working with a very dilute solution $\left(c a .2 \times 10^{-3} \mathrm{M}\right)$ of $\mathbf{1}$ in alkaline solution the product remained in solution. The changes in spectrum with time were recorded over 1000s and selected scans are shown in Figure 1.

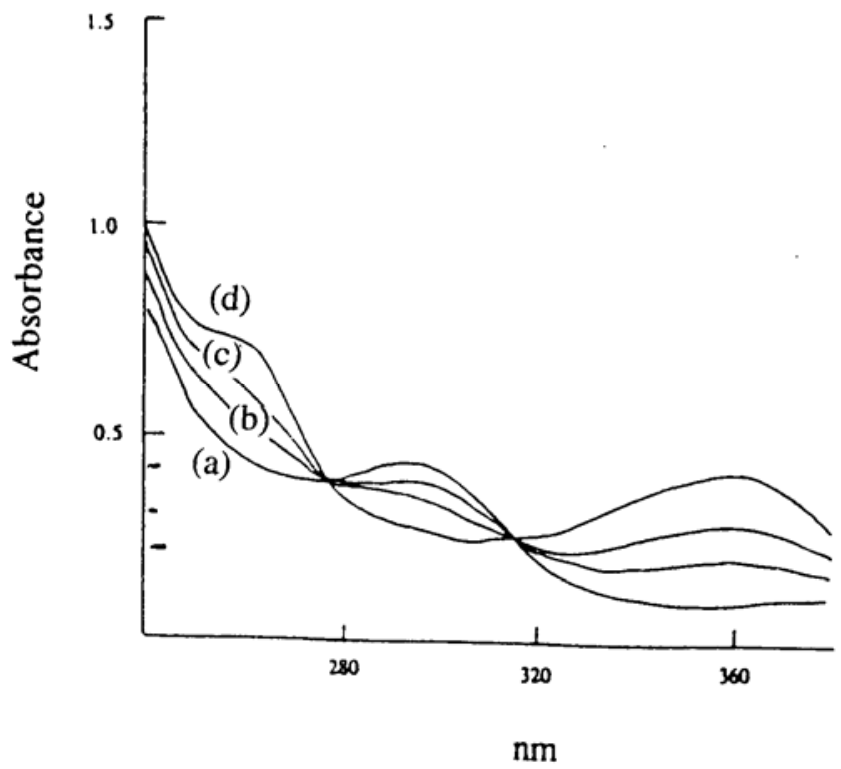

Figure 1. Variation of spectrum with time for the reaction of 1 at (a) 150, (b) 240, (c) 300 and (d) 367 secs. 
What is significant from these results is that there are two tight isosbestic points, showing that there is only one slow step in the formation of $\mathbf{4}$ from $\mathbf{1}$. All the other steps must be fast relative to the single, slow step. If two or more of the steps on the reaction pathway were of comparable rate, and much slower than the other steps, then the tight isosbestic points would be lost as the reaction proceeds. However, these results do not allow us to distinguish between the mechanism shown in Scheme 2 and one involving a slow enolisation step.

For the mechanism shown in Scheme 1 the most likely situation is that the slow step would be (a). All subsequent steps are intramolecular and, because of entropy considerations, likely to be faster than the initial intermolecular reaction and so the overall reaction for conversion of $\mathbf{1}$ into 4 should display second order kinetics. In the alternative mechanism where the slow step is enolisation of the $\alpha$-aminoketone the kinetics would be first order. These possibilities were examined.

The data from the spectral study showing the variation of absorbance at $300 \mathrm{~nm}$ with time are shown in the Table.

Table.

Variation of absorbance at $300 \mathrm{~nm}$ with time for the conversion of $\mathbf{1}$ into 4.

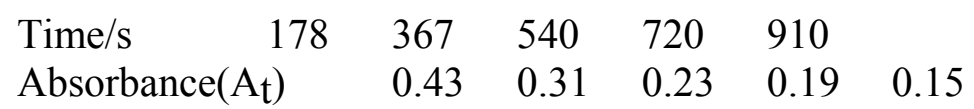

A plot of $\ln A_{t}$ against time is not rectilinear and so the reaction does not obey a first order rate law, arguing against enolisation of the aminoketone as the rate-determining step. Using the data in a second order plot is more complex as the absorbance data has to be converted into molarity of 1 and although it is easy to determine the extinction coefficient for $\mathbf{1}\left(\mathrm{e}_{1}\right)$ the product of reaction 4 also absorbs at $300 \mathrm{~nm}\left(\mathrm{e}_{2}\right)$. However, some trivial algebra indicates how $[\mathbf{1}]_{\mathrm{t}}$, the concentration of $\mathbf{1}$ at time $\mathrm{t}$, may be determined from the absorbance at time $\mathrm{t}\left(\mathrm{A}_{\mathrm{t}}\right)$.

$$
\begin{aligned}
& \mathrm{A}_{\mathrm{t}}=[\mathbf{1}]_{\mathrm{t}} \mathrm{e}_{1}+[\mathbf{2}]_{\mathrm{t}} \mathrm{e}_{2} \\
& \left.=[\mathbf{1}]_{\mathrm{t}} \mathrm{e}_{1}+0.5\left([\mathbf{1}]_{\mathrm{O}}\right)-[\mathbf{1}]_{\mathrm{t}}\right) \mathrm{e}_{2} \\
& {[\mathbf{1}]_{\mathrm{t}}=\frac{\mathrm{A}_{\mathrm{t}}-0.5[1]_{\mathrm{O}} \mathrm{e}_{2}}{\mathrm{e}_{1}-0.5 \mathrm{e}_{2}}}
\end{aligned}
$$

where $[\mathbf{1}]_{\mathrm{o}}$ is the initial concentration of $\mathbf{1}$. The initial and final values of the absorbance at $300 \mathrm{~nm}$ gave $\mathrm{e}_{1}$ and $\mathrm{e}_{2}$ as $0.25 \times 10^{3}$ and $0.21 \times 10^{2}$ respectively and the above equation was used to calculate $[\mathbf{1}]_{\mathrm{t}}$. For a bimolecular reaction with a single reactant obeying simple second order kinetics a plot of $1 /[\mathbf{1}]_{\mathrm{t}}$ against time should be linear ${ }^{3}$ and from Figure 2 this is seen to be the case. The second order rate constant for the reaction is $1.721 \mathrm{~mol}^{-1} \mathrm{~s}^{-1}$. We conclude, therefore, that Scheme 2 represents a reasonable mechanism for the condensation of two molecules of $\alpha$-aminoketone, with (a) as the slow, rate-determining step. What is interesting to 
note is the readiness with which steps in the condensation occur once the process becomes intramolecular.

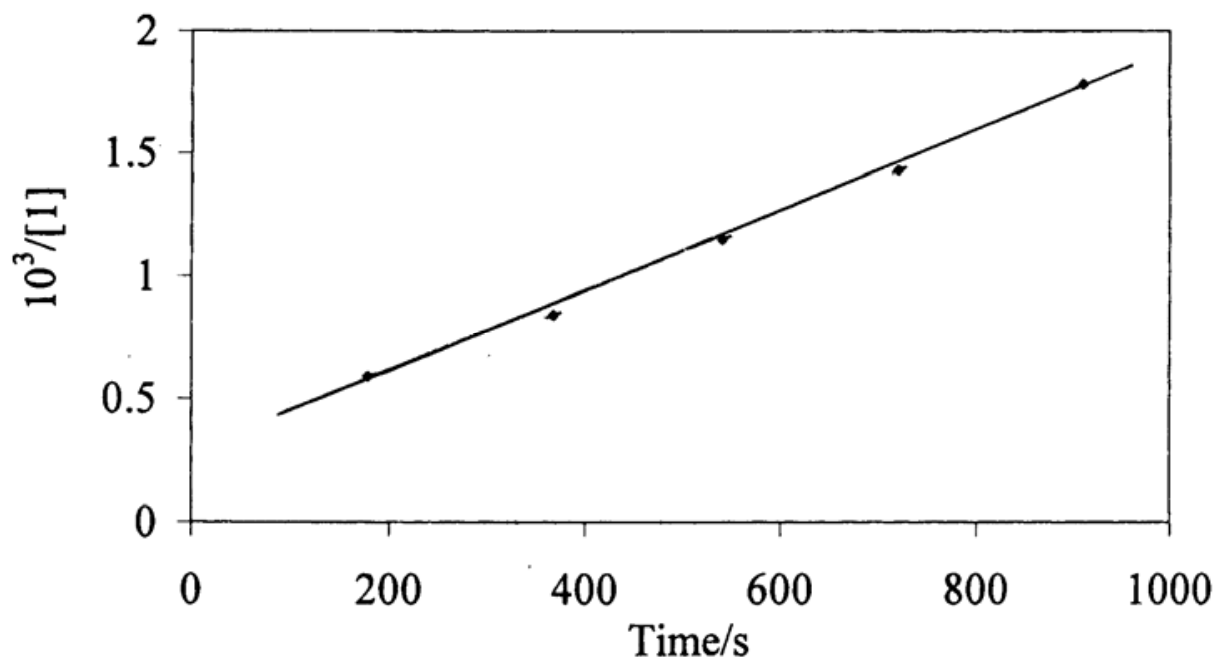

Figure 2. Second order plot for the reaction of $\mathbf{1}$.

\section{Experimental Section}

3-Nitro-4-hydroxycoumarin (6). A mixture of conc. nitric acid $\left(4.6 \mathrm{~cm}^{3}\right)$ and glacial acetic acid $\left(5 \mathrm{~cm}^{3}\right)$ was added to a suspension of 4-hydroxycoumarin $(10.1 \mathrm{~g}, 0.062 \mathrm{~mol})$ in glacial acetic acid $\left(25 \mathrm{~cm}^{3}\right)$. The mixture was heated to $70{ }^{\circ} \mathrm{C}$ to initiate the reaction and then allowed to cool to room temperature over $2 \mathrm{~h}$. The product was filtered off, washed with iced water and dried $\left(\mathrm{P}_{2} \mathrm{O}_{5}\right)$ to give a pale orange solid $(9.62 \mathrm{~g}, 75 \%)$, m.p. $178^{\circ} \mathrm{C}(\mathrm{dec})$, lit. $^{2} 177^{\circ} \mathrm{C}(\mathrm{dec}.) . \delta_{\mathrm{H}}(200$ $\mathrm{MHz},{ }^{2} \mathrm{H}_{6}$-DMSO) 7.3 (2H, m, aromatic), $7.6\left(1 \mathrm{H}, \mathrm{t}\right.$, aromatic) and $7.9\left(1 \mathrm{H}, \mathrm{d}\right.$, aromatic). $\delta_{\mathrm{C}}(50$ $\mathrm{MHz},{ }^{2} \mathrm{H}_{6}$-DMSO) 116.5, 120.0, 123.9, 125.8, 129.0, 133.4 (5 aromatic and $\left.\mathrm{CNO}_{2}\right), 152.6(\mathrm{CH})$, $157.0(\mathrm{COH})$ and $165.7(\mathrm{CO})$.

2-Hydroxy-2'-nitroacetophenone (7). 3-Nitro-4-hydroxycoumarin (4.0 g, $19.3 \mathrm{mmol}$ ) was dissolved in aq. $\mathrm{NaOH}\left(5 \mathrm{~g}\right.$ in $100 \mathrm{~cm}^{3}$ water). The solution was stirred at ca. $60{ }^{\circ} \mathrm{C}$ for $1.5 \mathrm{~h}$, during which time it turned bright orange. The solution was cooled and kept at room tempereature for $2 \mathrm{~h}$. Conc. $\mathrm{HCl}\left(15 \mathrm{~cm}^{3}\right)$ was added giving an immediate precipitate of pale yellow crystals which, after standing overnight, were filtered off $(2.1 \mathrm{~g}, 60 \%)$, m.p. $102-104{ }^{\circ} \mathrm{C}$, lit. ${ }^{2} 106{ }^{\circ} \mathrm{C} . \mathrm{m} / \mathrm{z}\left(\mathrm{EI}^{+}\right) 181\left(\mathrm{M}^{+}\right)$. Found: $\mathrm{C}, 52.9 ; \mathrm{H}, 4.2 ; \mathrm{N}, 7.7$ Calculated for $\mathrm{C}_{8} \mathrm{H}_{7} \mathrm{NO}_{4}$ : C, 53.0; H, 3.9; N, 7.7\%. $\delta_{\mathrm{H}}\left(200 \mathrm{MHz},{ }^{2} \mathrm{H}_{6}\right.$-DMSO) $6.2\left(2 \mathrm{H}, \mathrm{s}, \mathrm{CH}_{2}\right), 7.0$ (2H, m, aromatic), 7.6 $\left(1 \mathrm{H}, \mathrm{m}\right.$, aromatic), $7.8\left(1 \mathrm{H}, \mathrm{m}\right.$, aromatic) and $11.2(1 \mathrm{H}, \mathrm{s}, \mathrm{OH}) . \delta_{\mathrm{C}}\left(50 \mathrm{MHz},{ }^{2} \mathrm{H}_{6}-\mathrm{DMSO}\right) 91.1$ $\left(\mathrm{CH}_{2}\right), 122.8,123.3,124.9,125.2,135.8,136.0$ and 142.1 (aromatic), 165.0 (CO) and 166.8 (CO). The additional aromatic signals suggest that some of 7 may exist as the nitronic acid. 
2-Hydroxy-2'-aminoacetophenone hydrochloride (8). 2-Hydroxy-2'-nitroacetophenone (0.88 g, $5.34 \mathrm{mmol})$, tin(II) chloride dihydrate $(4 \mathrm{~g}, 20 \mathrm{mmol})$ and conc. $\mathrm{HCl}\left(6.7 \mathrm{~cm}^{3}\right)$ were stirred together. The temperature rose to $60{ }^{\circ} \mathrm{C}$ spontaneously and after 5 minutes the mixture was heated to $90{ }^{\circ} \mathrm{C}$ and left for 30 minutes. Water $\left(6.6 \mathrm{~cm}^{3}\right)$ was added and the mixture heated under reflux for 30 minutes to give a clear, yellow solution. The solution was cooled to $0{ }^{\circ} \mathrm{C}$ and stirred during the dropwise addition of $\mathrm{NaOH}$ solution $(10 \mathrm{M})$ until the $\mathrm{pH}$ rose to 5 . The brown precipitate was filtered off and dried $(0.52 \mathrm{~g}, 70 \%)$, m.p. $230{ }^{\circ} \mathrm{C}$, lit. ${ }^{2} 229-230{ }^{\circ} \mathrm{C}, \mathrm{m} / \mathrm{z}\left(\mathrm{EI}^{+}\right) 151$ $\left(\mathrm{M}^{+}\right) . \delta_{\mathrm{H}}\left(200 \mathrm{MHz},{ }^{2} \mathrm{H}_{6}\right.$-DMSO) $4.4\left(2 \mathrm{H}, \mathrm{s}, \mathrm{CH}_{2}\right) .7 .0(1 \mathrm{H}, \mathrm{t}$, aromatic), $7.2(1 \mathrm{H}, \mathrm{d}, 7.6(1 \mathrm{H}, \mathrm{t}$, aromatic) and $7.8\left(1 \mathrm{H}, \mathrm{d}\right.$, aromatic). $\delta_{\mathrm{C}}\left(50 \mathrm{MHz},{ }^{2} \mathrm{H}_{6}\right.$-DMSO) $53.8\left(\mathrm{CH}_{2}\right), 123.4,125.2,126.2$, 135.6 and 141.8 (aromatic) and $165.2(\mathrm{CO})$.

\section{Acknowledgements}

We thank the University of St Andrews for a maintenance grant and the Rollo Trust for funding.

\section{References}

1. Jaffe, E.K.; Rajagopalan, J.S. Biorg. Chem. 1990, 18, 381.

2. Huebner, C.F.; Link, K.P. J. Am. Chem. Soc. 1945, 67, 99.

3. Moore, J.W.; Pearson, R.G. Kinetics and Mechanism; J. Wiley: New York, 1981. 